\section{The Oxford Atlas}

Edited by Brigadier Sir Clinton Lewis and Colonel J. D. Campbell, with the assistance of D. P. Bickmore and K. F. Cook. Pp. 96+xxvi+90. (London: Oxford University Press, 1951.) 30s. net.

A MODERN atlas should show political and A natural features, include road communications and aerodrome sites as well as railways and have an index of all names shown on the maps, and, last but not least, should be relatively inexpensive. This "Oxford Atlas" fulfils these requirements. With pages slightly larger than 15 in. by 10 in., it consists of 120 pages of coloured maps (all specially drawn for this publication) and 88 pages of gazetteer entries (more than fifty thousand entries according to the reviewer's reckoning). The first 96 pages of maps cover all parts of the world and are of varying scales, coloured according to layer heights, and the other 24 are distribution maps of weather, population, land use, etc., the colours being used to indicate the relevant statistics.

For those who are more geometrically minded, perhaps the most intriguing part of the Atlas is the discussion of the types of projection used. Two tables give the distribution of errors over conical orthomorphic and transverse Mercator projections, and zenithal projections, respectively. Further, on each map there are figures in the border, those on the right-hand side showing the area in square miles (for that particular latitude) enclosed in the quadrilaterals formed by the parallels of latitude and longitude, and those on the left-hand side showing the distance in miles along each parallel of latitude between two successive meridians.

In the review copy received the detail of some of the maps is somewhat marred by poor workmanship in the colour printing; some obvious misalignments oan be seen, for example, where political and natural boundaries should coincide.

\section{Advances in Colloid Science}

Vol. 3. Edited by Prof. H. Mark and E. J. W. Verwey. Pp. xi+384. (New York and London: Interscience Publishers, Inc., 1950.) $60 \mathrm{~s}$.

D ROF. H. MARK is an international editor par excellence, and by his indefatigable travelling, lecturing, writing and editing in recent years has put all scientific workers in the field of colloid and polymer chemistry in his debt. Dr. E. J. W. Verwey, the other editor, provides an immediate link with the active Dutch school. The result of their editorial collaboration is the third volume of this useful series, which covers a variety of topics in the forefront of interest.

There is an excellent article by $J . H$. de Boer on atomic forces and adsorption in which he summarizes current theories of attractive and repulsive forces. A. E. Alexander discusses the application of surface chemistry to problems in colloid science and gives a number of interesting examples of which he has first-hand knowledge. G. Overbeek writes on a fundamental subject of which he is a masterthe quantitative interpretation of the electrophoretic velocity of colloids. The various factors influencing the derivation of the zeta potential are analysed.

Theories of lyogel structure, old and new, are the topic of E. A. Hauser and D. S. Le Beau. The peculiar properties of thixotropy, rheopexy and dilatancy are described, and hypotheses given to account for their nature. The ultracentrifuge and, in particular, the sedimentation properties of threadlike molecules are the concern of P.-O. Kinell and B. G. Ranby, of the Uppsala school. J. H. Dillon discusses at length the little-understood phenomena of fatigue in high polymers, while S. R. B. Cooke deals with flotation, one of the most recent methods for the concentration of minerals. Altogether, this is a most useful volume destined for a permanent home on the bookshelf.

\section{Ultrasonics}

By Dr. P. Vigoureux. Pp. vit l63. (London : Chapman and Hall, Ltd., 1950.) 25s. net.

$\mathrm{T}$ the number of books on ultrasonics which have 1 appeared on the market in recent years, this one takes an honoured place. Dr. P. Vigoureux does not, as a number of other writers do, emphasize the technical applications which have been made of this radiation--which, indeed, in many cases are more suited to the industrial laboratory than the production plant-but shows rather what has been done with ultrasonics in the physical laboratory. $\mathrm{He}$ begins with an account of the generation and detection of these waves by piezoelectric and magnetostrictive transducers, and briefly describes the methods of observation of the radiation in fluids. Then follows an accourt of velocity data and-more briefly-.. absorption data in gases and liquids, and the theories which have been put forward to explain them. This is as far as the survey goes and, in particular, propagation in solids is not discussed.

A comprehensive bibliography of some three hundred papers dealing with these topics since 1939 is included; but the author has not always been careful in consulting his references, as occasionally measurements are ascribed to the writer of a general article or to the rapporteur of a symposium rather than to the man of science who did the work so reported. This is, however, a small point and does not detract from the merit of this useful survey.

$$
\text { E. G. R. }
$$

Metallurgical Abstracts (General and Non-Ferrous) Editor : Lieut.-Colonel S. C. Guillan; Assistant Editor, Major W. G. Askew. Vol. 16, 1948-49. Pp. viii + 1048. (London: Institute of Metals, 1949.) $60 s$.

7 HIS volume fully maintains the high standard of scientific writing associated with "Metallurgical Abstracts", a publication which is a necessity for any scientific worker concerned with non-ferrous metallurgy. The abstracts are well and clearly written and give as much detail and numerical data as can be expected. The defect of the work lies in the uncertainty existing as to how much ferrous metallurgy is included. On the purely scientific side, ferrous and non-ferrous metallurgy are part of one subject, and the present system means that many scientific workers have to consult both the Metallurgical Abstracts of the Institute of Metals and those of the Journal of the Iron and Steel Institute if they are to keep in touch with their subject. Seeing that both Institutes occupy the same building, this pro. duction of independent abstracts with uncertain overlapping is scarcely to their credit ; and if a joint publication cannot be produced, metallurgists may reasonably ask for a common index. On the publica. tion side, the present volume is not well bound. One omission noted is that of a list of the journals ab. stracted.
W. HuME-ROTHERY 